\title{
Evaluation of the impact of various definitions of rurality on the prediction of prostate cancer progression
}

\author{
N. Lightfoot, B. Oddson, C. Berriault, R. Lafrenie, J. Abourbih, P. Legault, J. Macdonald, \\ R. Strasser
}

N. Lightfoot, $\mathrm{PhD}$

Associate Professor, Schools of Rural and Northern Health

Laurentian University

nlightfoot@laurentian.ca

B. Oddson, $\mathrm{PhD}$

Associate Professor, School of Human Kinetics

Laurentian University

boddson@laurentian.ca

C. Berriault, MA

Research Associate, Occupational Cancer Research Centre

Cancer Care Ontario

colin.berriault@occupationalcancer.ca

R. Lafrenie, $\mathrm{PhD}$

Scientist, Advanced Medical Research Institute of Canada

Medical Sciences Division, Northern Ontario School of Medicine

rlafrenie@amric.ca

J. Abourbih, MD

Clinical Sciences Division

Northern Ontario School of Medicine

jabourbih@nosm.ca

P. Legault, MD

Resident, Northern Ontario School of Medicine

Northern Ontario School of Medicine

plegault@nosm.ca

J. Macdonald, $\mathrm{PhD}(\mathrm{c})$

Student, Interdisciplinary PhD Program in Rural and Northern Health

Laurentian University

jm_macdonald@laurentian.ca

R. Strasser, MD

Dean, Northern Ontario School of Medicine

Northern Ontario School of Medicine

rstrasser@nosm.ca 
Diversity of Research in Health Journal / Revue de la Diversité de la Recherche en Santé Vol 1, pp 1-16, April 2017

\begin{abstract}
$^{1}$
This study evaluates whether three definitions of rural and urban residence predict prostate cancer progression. People were classified as urban or rural using three definitions: rural and small town (RST), Beale's rural-urban continuum codes, and the Rurality Index of Ontario (RIO) 2008 score. This was a chart-based cohort study of males with prostate cancer who underwent external beam radiation therapy (EBRT) in the Regional Cancer Program at Health Sciences North in Sudbury, Ontario from 1996 to 2003. Data indicative of each of the three definitions were used as predictors in Cox regression analysis for the period of 1,000 to 3,000 days after initial diagnosis and as the basis for dichotomous strata in a log rank test.

Complete data were acquired from 629 charts. There was no significant association between any of the three definitions of rurality and prostate cancer progression. However, a Beale-based dichotomization led to survival differences using the log rank test. Beale stratification was potentially sensitive to relevant differences in populations that were not represented by the other two definitions. Given the moderate correlations between the different rurality scores, there may be merit to considering multiple rurality scores as they may lead to different cancer progression outcomes in some situations.
\end{abstract}

Key words: prostate cancer, progression, predictors, definitions of rurality

\title{
Résumé
}

Cette étude évalue si trois définitions de la résidence rurale et urbaine prédisent la progression du cancer de la prostate. Les personnes ont été classées comme urbaines ou rurales en utilisant trois définitions: la ville rurale et la petite ville (RST), les codes de milieu continu urbain-urbain de Beale et le score de l'indice Rurality Index of Ontario (RIO) 2008. Il s'agissait d'une étude de cohorte à base de diagrammes sur les hommes atteints de cancer de la prostate qui ont subi une radiothérapie externe (EBRT) dans le programme régional de cancer de Sciences de la santé Nord à Sudbury, en Ontario, de 1996 à 2003. Des données indicatives de chacune des trois définitions ont été utilisées Comme prédicteurs dans l'analyse de régression de Cox pour la période de 1.000 à 3.000 jours après le diagnostic initial et comme base pour les strates dichotomiques dans un test de rangs.

Les données complètes ont été acquises à partir de 629 graphiques. Il n'y a pas eu d'association significative entre l'une des trois définitions de la progression de la ruralité et du cancer de la prostate. Cependant, une dichotomisation basée sur Beale a entraîné des différences de survie en utilisant le test de log rank. La stratification de Beale était potentiellement sensible aux différences pertinentes dans les populations qui n'étaient pas représentées par les deux autres définitions. Compte tenu des corrélations modérées entre les différents scores de la ruralité, il peut y avoir du mérite de considérer les scores de la ruralité multiple car ils peuvent conduire à des résultats de progression du cancer différents dans certaines situations.

Mots clés: cancer de la prostate, progression, prédicteurs, définitions de la ruralité

\footnotetext{
${ }^{1}$ Correspondence concerning this article should be addressed to: Nancy Lightfoot, School of Rural and Northern Health, Laurentian University, 935 Ramsey Lake Rd., Sudbury, Ont., P3E 2C6, SE-205 F; Telephone: 1-705-675-1151 ext. 2972; Fax: 1-705-671-6603. Email nlightfoot@laurentian.ca.
} 
Diversity of Research in Health Journal / Revue de la Diversité de la Recherche en Santé Vol 1, pp 1-16, April 2017

\section{Evaluation of the impact of various definitions of rurality on the prediction of prostate cancer progression ${ }^{2}$}

Prostate cancer continues to be the leading cause of cancer in Canadian and American men, second to colorectal cancer (Canadian Cancer Society's Advisory Committee on Cancer Statistics [CCS], 2016). The relative five-year survival rate overall for prostate cancer is now 95\% (CI: 94-95\%) in Canada (CCS, 2016) and 100\% for localized or regional disease in the United States (National Cancer Institute [NCI], 2013). Risk factors for the disease remain elusive. While age, ethnic-geographical, and genetic factors are predominant, others such as: hormonal, anthropometric, history of hypertension and perinatal factors have displayed discrepant results (Ferris-i-Tortajada, Garcia-i-Castell, Berbel-Tornero, \& Ortega-Garcia, 2011). Several researchers found that inflammation, triggered by infection with various agents and other factors, can underlie the development of prostate cancer (Carozzi et al., 2003; Davidsson et al., 2016; Klein \& Silverman, 2008; Leung, McKenzie, Martin, \& McLaughlin, 2014; Lightfoot et al., 2004; Sutcliffe et al., 2016).

Risk factors that influence the development of prostate cancer, however, may differ from those that influence progression and survival ( $\mathrm{Zu} \&$ Giovannucci, 2009). Given that more men are being diagnosed at early stage disease, leading to increased survival and improved quality of life, prostate cancer progression and associated predictors are now receiving much attention (Buhmeida, Pyrhönen, Laato, \& Collan, 2006). Predictors of prostate cancer progression include: Gleason score, tumour stage, positive surgical margins at diagnosis, and tumour volume (Boorjian, Tollefson, Rangel, Bergstralh, \& Karnes, 2012; Ploussard et al., 2011). In addition, the roles of age, genetic factors, diet, smoking, fluctuations in hormone levels (including testosterone, leptin, and adiponectin), metabolic syndrome components (including obesity, hypercholesterolaemia, diabetes, and hyperinsulinaemia), prostate volume, the percent and number of positive biopsies cores and the maximal involvement of a single core at initial diagnosis, the initial PSA (prostate specific antigen), PSA density, PSA velocity, percent free-tototal PSA, PSA doubling time, and rapid PSA doubling time (i.e., less than six months doubling time), worst Gleason scores (i.e., Gleason score of 6 or less versus higher and Gleason score of 7 or less versus higher), and more have been associated with prostate cancer progression (Boorjian, Tollefson, Thompson, et al., 2012; Ploussard et al., 2011; Rhee, Vela, \& Chung, 2016; Tolonen et al., 2011; Venkitaraman et al., 2007; Zu \& Giovannucci, 2009).

What defines a "rural" population has been discussed extensively, internationally, without a general consensus. In a review, Couper (2003) indicated that most definitions of rural consider service, access, and remoteness (distance). He proposed that rural health care relates to the provision of health services to areas outside of metropolitan centres where there is not ready specialist access, and where human and material resources are lacking (Couper, 2003). Some studies have considered the impact of rural and urban residence on prostate cancer progression. Various studies have shown that rural populations have poorer chronic disease outcomes and

\footnotetext{
2 The authors thank Dr. Roger Pitblado (Professor Emeritus and Senior Research Fellow, Centre for Rural and Northern Health Research, Laurentian University) for the use of his computer programs that linked postal codes of residence with community locations and subsequently to the rural-urban continuum categories of the three rurality definitions employed in this paper. We are most grateful for clinical assistance provided by Dr. Randy Bissett, of the Regional Cancer Program, at Health Sciences North in Sudbury. We would also like to thank the Northern Cancer Foundation (NCF) as this study would not have been possible without their funding and support.
} 
Diversity of Research in Health Journal / Revue de la Diversité de la Recherche en Santé Vol 1, pp 1-16, April 2017

have cancers detected at more advanced stages than urban populations (Leung et al., 2014; Pong, DesMeules, \& Lagacé, 2009; Singh, Williams, Siahpush, \& Mulhollen, 2012), although other studies have shown no differences (Shugarman, Sorbero, Tian, Jain, \& Ashwood, 2008). The varied findings may be attributed to differential access to medical resources that may lead to different outcomes; conversely, rural and urban populations may also differ in exposures. However, the capacity to detect any actual difference in residence depends, at least in part, on the ability to correctly classify people according to any relevant differences in residence. This study examined the potential impact of rural and urban residence on prostate cancer progression with special attention paid to utilizing various definitions of rural and in identifying other potential predictors of progression (Baade, Youlden, Coory, Gardiner, \& Chambers, 2011; McLafferty \& Wang, 2009; Monroe, Ricketts, \& Savitz, 1992; Pong et al., 2009).

Similarly, in Canada, many definitions of a rural population have been proposed for use in health policy and other venues. Six of these definitions were compared by the Agriculture Division at Statistics Canada for use in national and provincial analysis (du Plessis, Beshiri, Bollman, \& Clemenson, 2002). Each definition emphasized different criteria (e.g., population size, density, and context), had different population thresholds, and was based on varying territorial units (du Plessis et al., 2002). Du Plessis et al. (2002) emphasized that differing definitions result in different people being classified as "rural," but maintained that similar analytical conclusions should still result. They suggested that selecting a definition needs to be based on the question being addressed, the desired territorial unit, and the geographic dimensions of concern (e.g., population size, population density, labour market, or settlement context). They selected the "rural and small town" (RST) definition of rural (du Plessis, Beshiri, Bollman, \& Clemenson, 2001; du Plessis et al., 2002) as the benchmark for understanding Canada's rural population and identify a rural population as one where the population of the core community is less than 10,000 persons and where the communities are outside the commuting zone of larger urban centres. This is in contrast with the BEALE definition (du Plessis et al., 2001, 2002) which focuses on the distinction between metropolitan regions and rural spaces, and the Rurality Index for Ontario continuous scores (RIO) (Kralj, 2009).

The three aims of study were to determine: 1) if rural residence was a predictor of prostate cancer progression, 2) whether any of the three rurality definitions were differentially sensitive to prostate cancer progression, and 3) whether any such differences were likely to reflect meaningful differences in exposure or treatment.

\section{Methods}

This retrospective cohort chart-based study received ethics approval from the Sudbury Regional Hospital Research Ethics Committee and the Laurentian University Research Ethics Board. The charts of patients with a diagnosis of histologically confirmed primary ICD9 code 185 prostate cancer who were residents of northeastern Ontario, Canada, and treated with external beam radiation therapy (EBRT) for the period 1996 to 2003 were identified in the electronic database held by Health Information Services at the Regional Cancer Program (RCP), Sudbury Regional Hospital (now known as Health Sciences North) (Medicode (Firm), 1996) EBRT patients represent the largest group of prostate cancer patients treated in the RCP (Bissett, 2008) . Men who received radiation treatments less than 5,000 Gray or who were diagnosed with metastatic disease were not included in the study as many of these patients were palliative cases that were not treated with curative intent. Patient charts were retrieved, reviewed and information was entered into a spreadsheet and then analyzed using Stata 14 (StataCorp, 2015). 
Diversity of Research in Health Journal / Revue de la Diversité de la Recherche en Santé Vol 1, pp 1-16, April 2017

\section{Rurality Measures}

The three definitions of a rural population considered in this study were: 1) Rural and Small Town (RST) (du Plessis et al., 2001, 2002), 2) the BEALE classification (du Plessis et al., 2001, 2002), and 3) the Rurality Index for Ontario (RIO) score (Health Force Ontario [HFO], 2015; Kralj, 2009). Postal codes of residence, at first cancer centre visit, were obtained from the hospital charts for each patient included in the study. A computer program that employed data from postal code conversion files was then used to link the patients' communities of residence to the rural-urban continuum categories of each of the three rurality definitions outlined above (Lightfoot, 2009; Statistics Canada, 2012).

The RST definition allocates individuals as rural if they live in towns or municipalities (census subdivisions) outside the commuting zone of larger urban centres, that is, outside census metropolitan areas and outside census agglomerations, with populations of greater than 10,000 persons (du Plessis et al., 2001, 2002). In accordance with this definition, urban areas with core populations under 10,000 are also considered rural if they are outside the main commuting zones of larger urban centres. The second definition of rural considered in this study, the BEALE definition, was developed by the United States Department of Agriculture (USDA) (2014) in 1974 (updated each decennial), as a rural-urban continuum classification scheme that distinguishes metropolitan counties by size and non-metropolitan counties by degree of urbanization and proximity to metropolitan areas (du Plessis et al., 2001, 2002). The USDA BEALE codes were last adapted for use in Canada in 1996 and based on census divisions, where individuals living outside of metropolitan regions with urban centres of more than 50,000 in population, or in regions with no urban settlements (places with a population of less than 2,500 people) are considered rural (du Plessis et al., 2001, 2002). The RIO is a continuous score developed by the Ontario Medical Association, that is used extensively by the Province of Ontario, Ministry of Health and Long-Term Care, that considers travel time to the nearest basic referral centre, travel time to the nearest advanced referral centre, community population, the number of active general practitioners (GP) and population-to-GP ratios, the presence of a hospital, availability of ambulance services, social indicators, weather conditions, and selected services (du Plessis et al., 2002). As of 2010, a physician or a nurse is designated as rural by the Province of Ontario if he or she practices in a community that has a RIO score of 40 or above (Health Force Ontario [HFO], 2015).

\section{Prostate Cancer Progression Measures}

In this study, prostate cancer progression was defined as the first occurrence of one of the following events: : 1) biochemical recurrence (i.e., a rise by $2 \mathrm{ng} / \mathrm{mL}$ or more above the absolute nadir (lowest) value for PSA); 2) receipt of secondary therapy in the form of radiotherapy, antineoplastic (chemotherapy), or hormonal agents started after the original course of radiation therapy; 3) biopsy-proven local disease recurrence; or 4) evidence of distant metastatic progression by bone scan or other tests (Mallah, DiBlasio, Rhee, Scardino, \& Kattan, 2005). This definition was selected because it was feasible, practical, valid, and has been used by other studies of prostate cancer progression (Furuya, Akimoto, Akakura, \& Ito, 1998; Mallah et al., 2005; Pantarotto, Malone, Dahrouge, Gallant, \& Eapen, 2007). The Houston definition of biochemical failure was used and consists of a rise by $2 \mathrm{ng} / \mathrm{mL}$ or more above the absolute nadir value for PSA (Roach et al., 2006). This definition has greater sensitivity and specificity, and is more appropriate for patients treated with EBRT compared to definitions of failure based on the 
Diversity of Research in Health Journal / Revue de la Diversité de la Recherche en Santé Vol 1, pp 1-16, April 2017

PSA level rising above a fixed threshold. It is the standard definition of biochemical failure after EBRT, and has adequate follow-up (i.e., more than three years) (Thames et al., 2003).

The patient records were examined to find the Post-EBRT PSA levels that were the lowest (nadir) value, and then follow-up PSA values were reviewed: if a value greater than 2 $\mathrm{ng} / \mathrm{mL}$ was achieved, biochemical failure was deemed to have occurred. If hormonal agents were administered after completion of the EBRT, then recurrence was deemed to have occurred based on a review of the physician prescriptions. Recurrence was also defined when the progression of disease was detected by positive biopsy-proven local disease recurrence after completion of the EBRT. Evidence of distant metastatic progression by bone scan, MRI (magnetic resonance imaging), CT (computerized axial tomography) scan, or other tests also confirmed disease recurrence.

\section{Statistical Methods}

Stata 14 software was used for statistical analysis in this study (StataCorp, 2015). To identify factors associated with the odds of prostate cancer progression a preliminary logistic regression analysis was conducted. Time to progression was then modelled using Cox regression analysis. It was found, contrary to model assumptions, that initial tumour type, age, and initial PSA score were associated with time-varying relationships with progression risk. Accordingly, analysis was focused on 1) rural or urban residence at the first cancer centre visit (using each of the three definitions), 2) age at diagnosis as a continuous variable, 3) family history of prostate cancer in a father or brother, 4) Gleason score at diagnosis, 5) initial continuous pre-treatment PSA at diagnosis, and 6) a history of diabetes over the interval of 1,000 to 3,000 days postinitial diagnosis.

Finally, rurality scores were dichotomized and used as the stratification for the three $\log$ rank survival tests. For the rural and small town definition, a rural population was under 10,000 and urban was 10,000 and over, for the RIO definition, rural was considered to be a score of 40 and up and the remainder urban, and for the BEALE definition none of the BEALE categories corresponded to either of the other two definitions so the BEALE score was selected to dichotomize urban and rural populations based on examination of the data. Kaplan-Meier survival plots were generated to display the time to progression in days for each. Subjects were removed from the analysis upon their first progression event as defined previously.

\section{Results}

\section{Patient Characteristics}

Of the initial 1,446 patients with prostate cancer who underwent radiotherapy at the northeastern Ontario regional cancer center and had charted first visit follow-up data, 629 were eligible to undergo the analyses based on completeness of the data (and the appropriate time interval). There was no significant difference in attrition between urban and rural sub-groups.

Figure 1 shows the rates of prostate cancer incidence by Ontario, Canada census division for the period of 1996 to 2003 (Cancer Care Ontario [CCO], 2012). The base-line demographic and clinical characteristics of the entire cohort are presented in Table 1 . The mean age for those not showing signs of prostate cancer progression was 68.7 years of age $($ s.d. $=6.1)$. For those with signs of prostate cancer progression, the mean age $t$ was 67.3 years of age $($ s.d. $=6.8)$. Over sixteen $16 \%$ of patients were diabetic, while over $17 \%$ had a blood relative who had been diagnosed with cancer. Gleason scores at diagnosis for patients with evidence of prostate cancer 
progression varied from $4 \%$ for those below a score of 5, to $67 \%$ for those with a score between 5 and 7, and 29\% for those with scores between 8 and 10. The mean for blood prostate specific antigen (PSA) levels at diagnosis was $13.2 \mathrm{ng} / \mathrm{mL}($ s.d. $=14.8)$ for those without signs of progression and $16.7 \mathrm{ng} / \mathrm{mL}($ s.d. $=16.4)$ for those with signs of progression.

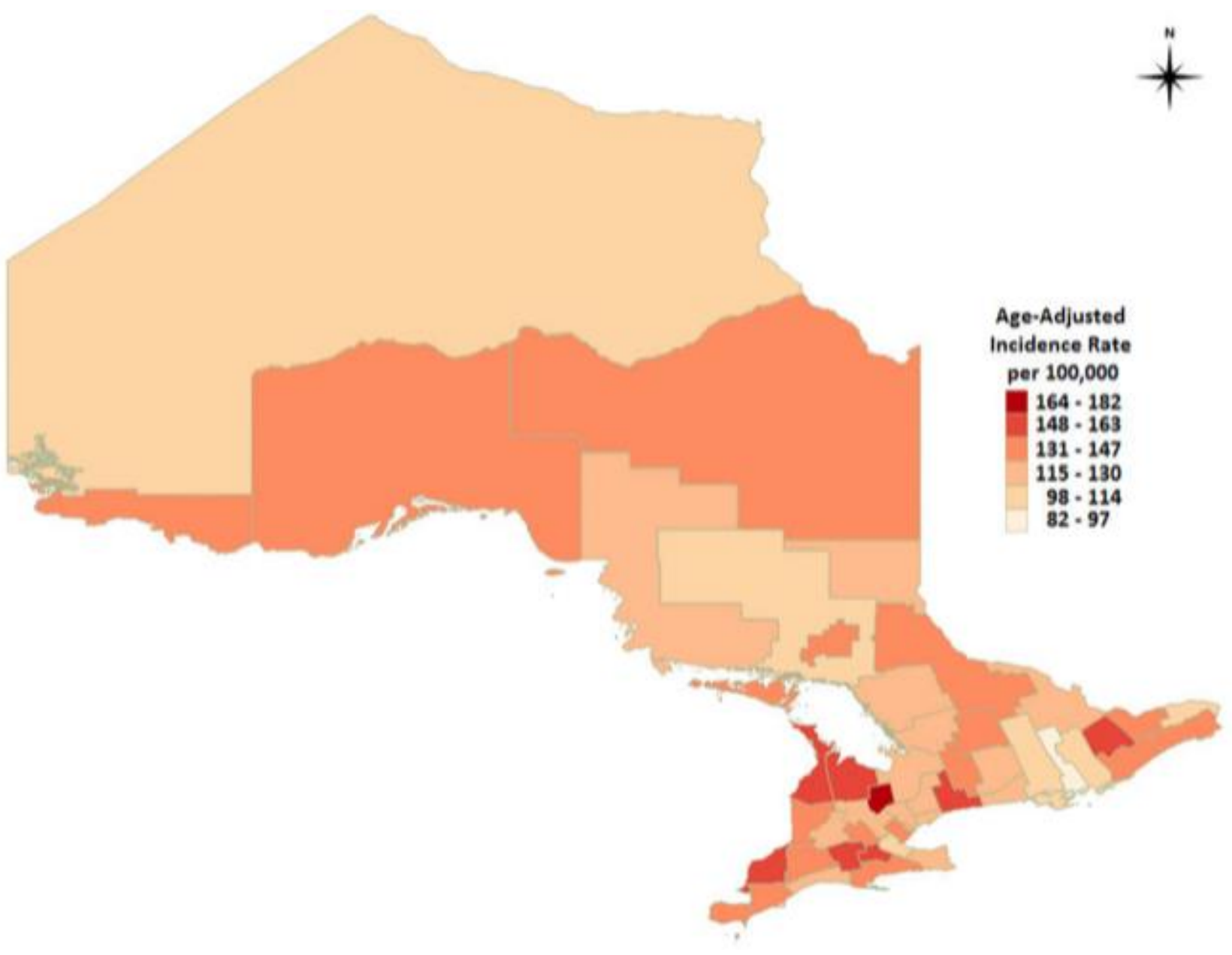

Figure 1. Map of Ontario, Canada: Rates of Prostate Cancer Incidence (1996 - 2003) Disaggregated by Census Division. This map displays the rates of prostate cancer incidence for the period of 1996 to 2003. Retrieved from "SEER * Stat - OCRIS. Release 12" by Cancer Care Ontario [CCO], 2012, available online at: https://www.cancercare.on.ca/cancerfacts. 
Diversity of Research in Health Journal / Revue de la Diversité de la Recherche en Santé

Vol 1, pp 1-16, April 2017

Table 1

Base-line Demographic and Clinical Participant Characteristics $(n=629)$

\begin{tabular}{lccc}
\hline \hline & $\begin{array}{c}\text { No progression } \\
(\mathrm{n}=490)\end{array}$ & $\begin{array}{c}\text { Progression } \\
(\mathrm{n}=139)\end{array}$ & $\mathrm{p}$-Value \\
\hline Age at diagnosis (years) & 68.7 (s.d. 6.1) & 67.3 (s.d. 6.8) & $0.023^{*}$ \\
\hline Blood PSA at diagnosis & 13.2 (s.d. 14.8) & 16.7 (s.d. 16.4) & $0.027^{*}$ \\
\hline Diabetes status & $85(17 \%)$ & $21(15 \%)$ & 0.55 \\
\hline $\begin{array}{l}\text { Gleason Score at } \\
\text { Diagnosis }\end{array}$ & & & $\begin{array}{c}0.047 \text { by MW U } \\
\text { or 0.139 by } \\
\text { CHISQ }\end{array}$ \\
\hline \multicolumn{1}{c}{$6-5$} & $5 \%$ & $6 \%$ & \\
\hline \multicolumn{1}{c}{$8+$} & $75 \%$ & $65 \%$ & \\
\hline $\begin{array}{l}\text { Cancer in a blood relative } \\
\text { (father and/or brother) }\end{array}$ & $85(17 \%)$ & $29 \%$ & 0.34 \\
\hline
\end{tabular}

Note. PSA = prostate-specific antigen; s.d. = standard deviation; MW U = Mann-Whitney U test; CHISQ = chi-square

$* \mathrm{p}<0.05$

\section{Risk of Cancer Progression}

Backward stepwise logistic regression was used to establish the best possible model of prostate cancer progression with the available data. Independent variables included in the final model were: age at diagnosis; diabetes status; blood PSA at diagnosis; Gleason score at diagnosis; and, Rural Small-Town, BEALE, and Rural Index for Ontario rurality measures. Cancer in a father and/or brother was also considered, but had inadequate explanatory power. When smoking history, tumour stage at diagnosis, and BMI (body mass index) at first cancer centre visit, were considered, there was too much missing data for them to be included in the model.

The association between rurality and risk of cancer progression was then studied using a series of Cox regression models. Over the time period of 0 to 1,000 days, Gleason stage at diagnosis dominated the other terms of the model but violated the proportionate hazards assumption, $\mathrm{p}=0.03$ (Table 2). A proportional hazards model could be justified from 1,000 to 3,000 days post treatment. Over this interval, time to progression could be predicted by blood PSA at diagnosis, $\mathrm{p}<0.01$, Gleason score at diagnosis, $\mathrm{p}<0.01$, and age at diagnosis, $\mathrm{p}<0.01$ 
Diversity of Research in Health Journal / Revue de la Diversité de la Recherche en Santé Vol 1, pp 1-16, April 2017

each predicted the rate of cancer progression. Diabetes made no contribution. None of the three rurality scores were associated with risk of cancer progression.

Table 2

Cox Regression Model for Prostate Cancer Progression

\begin{tabular}{lccc}
\hline Parameter & HR & $95 \%$ CI & p-Value \\
\hline Blood PSA at diagnosis & 1.02 & $1.01-1.03$ & $<0.01^{*}$ \\
\hline Gleason score at diagnosis & 1.59 & $1.17-2.15$ & $<0.01^{*}$ \\
\hline Diabetes Status at diagnosis & 0.94 & $0.67-1.33$ & 0.75 \\
\hline Age at diagnosis & 0.96 & $0.94-0.99$ & $<0.01 *$ \\
\hline RST & 0.76 & $0.40-1.44$ & 0.40 \\
\hline RIO & 1.30 & $0.71-2.38$ & 0.39 \\
\hline BEALE & 1.26 & $0.82-1.93$ & 0.30 \\
\hline
\end{tabular}

Note. RST $=$ Rural and Small Town; BEALE = Beale Canadian Classification. Adapted from "Definitions of Rural," by V. du Plessis, R. Beshiri, R. D. Bollman, and H. Clemenson, 2001, Rural and Small Town Canada Analysis Bulletin, 3(3). P. 17.

${ }^{a}$ RIO = rurality index for Ontario. Adapted from "Measuring Rurality - RIO2008_BASIC: Methodology and Results," by B. Kralj, 2008, Ontario Medical Association, available online at: https://www.oma.org/Resources/Documents/2008RIO-FullTechnicalPaper.pdf.

${ }^{\mathrm{b}} \mathrm{PSA}=$ prostate-specific antigen; $\mathrm{HR}=$ hazard ratio; $\mathrm{CI}=$ confidence interval. $* \mathrm{p}<0.05$.

\section{Differences in Progression Stratified by Rurality Scores}

Time to progression can also be evaluated using a log rank test where rural and urban populations are treated as separate strata (Figure 2). These tests are potentially more sensitive to the impact of rurality. Therefore the relative risks for urban and rural populations were evaluated in three different stratified models, one for each classification scheme (Table 3). Results for time to progression, using the two separate strata for each definition, are presented in Table 3 . These results suggest that the relative risk of progression appears to be different only when the population is stratified using the Beale classification, $\mathrm{p}<0.03$. 

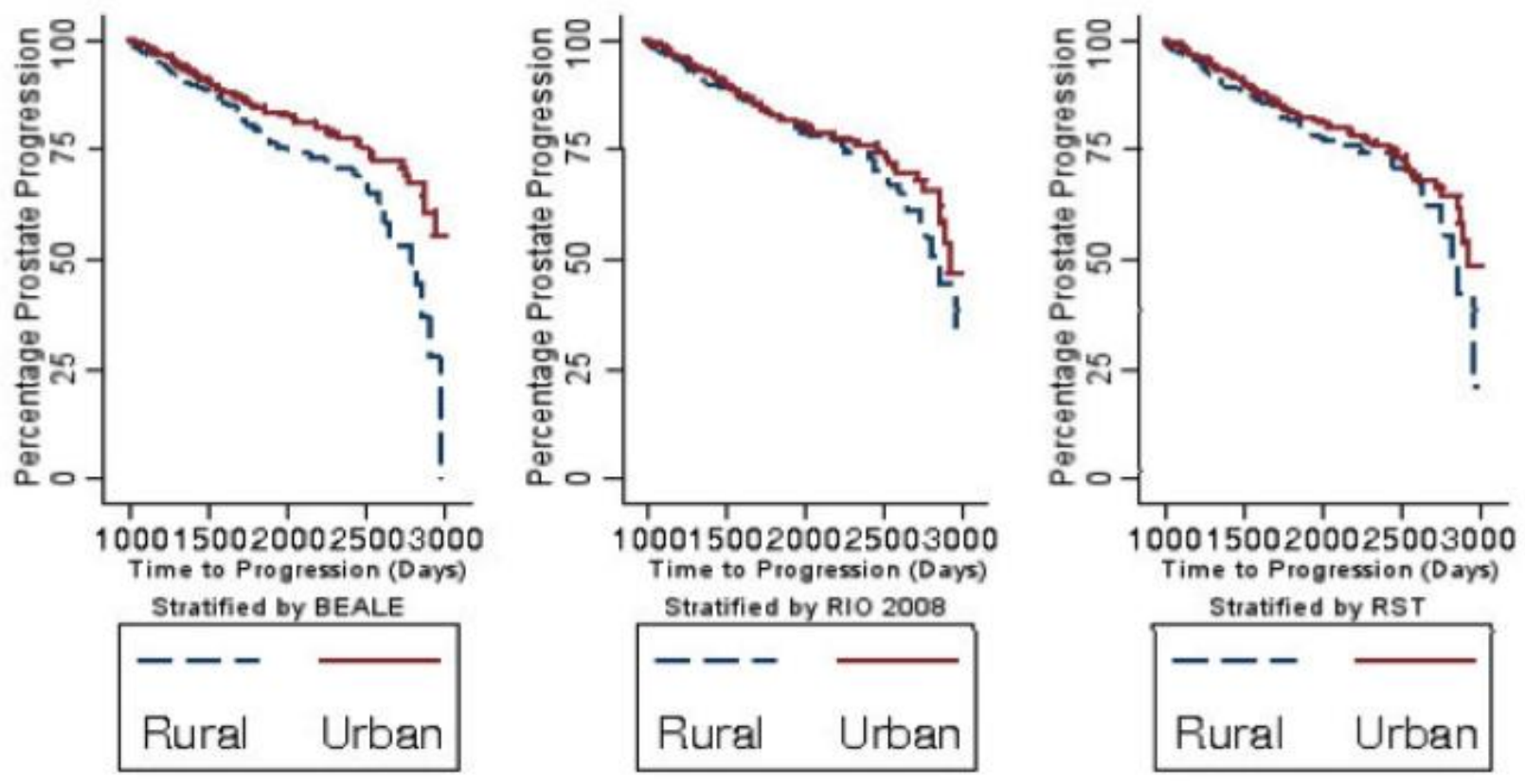

Figure 2.0. Proportional Rurality-Definitions' Hazards Model. A Kaplan-Meier proportional hazards model, comparing (using the log-rank test) urban-rural differences in 'time to prostate cancer progression' between the three definitions of rurality being used for this study; RST, BEALE, and RIO.

Table 3

Relative Risk of Prostate Cancer Progression by Dichotomized Rurality Scores

\begin{tabular}{lccc}
\hline Parameter & RR & $95 \%$ CI & p-Value \\
\hline BEALE & 0.65 & $0.46-0.90$ & $0.009 *$ \\
\hline RST & 1.19 & $0.85-1.67$ & 0.30 \\
\hline RIO & 0.86 & $0.62-1.20$ & 0.37 \\
\hline
\end{tabular}

Note. RST $=$ Rural and Small Town; BEALE = Beale Canadian Classification. Adapted from "Definitions of Rural," by V. du Plessis, R. Beshiri, R. D. Bollman, and H. Clemenson, 2001, Rural and Small Town Canada Analysis Bulletin, 3(3). P. 17.

${ }^{a}$ RIO = rurality index for Ontario. Adapted from "Measuring Rurality - RIO2008_BASIC: Methodology and Results," by B. Kralj, 2008, Ontario Medical Association, available online at: https://www.oma.org/Resources/Documents/2008RIO-FullTechnicalPaper.pdf.

${ }^{\mathrm{b}} \mathrm{RR}=$ relative risk; $\mathrm{CI}=$ confidence interval. $* \mathrm{p}<0.05$. 
Diversity of Research in Health Journal / Revue de la Diversité de la Recherche en Santé Vol 1, pp 1-16, April 2017

\section{Discussion}

It is common to find studies utilizing differing rural and urban definitions based on various national, and even regional, classification schemes (Obertova, Brown, Holmes, \& Lawrenson, 2012). More recently, definitions have tended to focus on geographical descriptions, economic aspects, and healthcare resource accessibility (Baade et al., 2011; Obertova et al., 2012).

Some have suggested that many observed health outcome trends may be attributed, in part, to the urban-rural definition used (Hart, Larson, \& Lishner, 2005; Mahoney, Labrie, Nasca, Wolfgang, \& Burnett, 1990; Obertova et al., 2012). In addition, Coory and Baade (2005) observed that differences in mortality trends could be attributable to using the same data with different lengths of follow up period.

In the present study, we examined prostate cancer progression using logistic regression to identify a set of predictors and then cox regression analysis to model time to progression. In Cox regression models over the period of 1,000 to 3,000 days post diagnosis, none of the three dichotomized urban-rural classification schemes showed a significant association with progression. In log rank tests where risk is stratified by urban-rural dichotomies there was a clear difference between strata only when the Canadian-adapted Beale classification was used. This discrepancy suggests that it is most likely that any impact of rurality is through the known covariates. Cox regression adjusts for these and found no impact of rurality. This is interesting in light of some reports that suggest that rural areas tend to have both lower rates of PSA screening and a later clinical stage at diagnosis (Jemal et al., 2005; Pampalon, Martinez, \& Hamel, 2006). Prostate cancer incidence and PSA screening uptake tends to be higher in urban males and mortality is higher in rural males (Desmeules et al., 2006; Obertova et al., 2012). After approximately eight years of follow-up, $50 \%$ of the rural subjects had experienced prostate cancer progression.

The differences in the ability of the three definitions of a rural population to predict prostate cancer time to progression may be based on functional differences in the definitions and their applicability to northeastern Ontario. The RST definition refers to rural populations as those outside centres with populations of 10,000 or more and may be further disaggregated into zones according to the degree of influence of a larger urban centre. The RIO score calculates the degree of rurality based on three factors strictly related to the use of healthcare services: travel time to a basic referral centre; travel time to an advanced referral centre; and, count and density of population. This makes determining a strict cutoff of this continuous score somewhat subjective (du Plessis et al., 2002; Health Force Ontario [HFO], 2015). The BEALE definition of rurality defines a rural population as those with individuals living outside urban centres with a population of more than 50,000 persons (du Plessis et al., 2002). The main difference with this and the RST score is that while both rely on census divisions to order their classifications, the BEALE definition represents essentially the middle size rural definition. This may have made it a more natural fit to the region under study. In northeastern Ontario there are few urban centres with populations of more than 50,000 and small towns and municipalities below 10,000 predominate. Thus, for this region with relatively light population density, the BEALE definition may be a better method for detecting differences present between urban and rural populations than are the definitions that are better suited to more densely populated regions. The correlations between the various rurality scores are moderate, not high. Accordingly, it is probably relevant for future researchers to consider more than one rurality definition when investigating predictors of cancer progression where possible. 
Diversity of Research in Health Journal / Revue de la Diversité de la Recherche en Santé Vol 1, pp 1-16, April 2017

\section{Limitations}

This study included those diagnosed with prostate cancer that had undergone radiotherapy at the cancer centre in Sudbury and would not include those who may have moved, who had various residences, and who attended a different cancer centre during the follow up period of 1996 to 2003, although these would be expected to be minimal in this age group.

There is a risk of introducing a fair degree of heterogeneity when pooling several categories in a classification scheme, such as dichotomizing categories of a definition or collapsing categories where very low population density might decrease the size of subsequent sub-groups (Alam, You, Banks, Baker, \& Bishop, 2009). Thames et al., (2003) noted that that many studies utilized larger areas such as counties and municipalities in their schemes as the basic geographical unit, thereby reinforcing this heterogeneity effect.

Finally, in contrast to the decennially updated US BEALE codes, the Canadian-adapted BEALE scheme was last modified in 1996, which may not accurately reflect or accommodate for social, political, economical and migrational changes over the last 21 years (Bruce, Halseth, Giesbrecht, \& Yen, 2004; du Plessis et al., 2002; [USDA], 2014). Additionally, the use of adapted BEALE codes for use in Canada has been methodologically criticized based on significant conceptual and practical differences in definitions such as 'access of services,' 'geographic distance between services, 'lack of transportation infrastructure,' and 'cost of transportation' (Bruce et al., 2004). Conceptual differences may limit the applicability of using Canadian-adapted BEALE codes in a northerneastern Ontario context (Bruce et al., 2004; du Plessis et al., 2002; Hart et al., 2005).

\section{Conclusions}

No definition of rurality explored in this study was directly associated with prostate cancer progression therefore this study is not suitable for deciding which definition is most suitable for that use. However, Obertova et al. (2012) have observed that the definition of rurality selected can impact health outcomes . Different definitions lead to different breakdowns with possible consequences beyond du Plessis' assertions, though none appear more informative than another (du Plessis et al., 2001, 2002) . In the present study, the BEALE definition of nonmetropolitan areas was only marginally significantly associated with time to prostate cancer progression in the northeastern Ontario study population in the sense that urban and rural populations appear to have different risks over one particular time period. However, the three definitions of rurality are related to each other, and the same stratification using the other definitions did not lead to the same results. Using Cox regression analysis the impact of rurality was minimal. This suggests that the impact of rurality is captured by the demographic and treatment variables that were shown to be important in the Cox regression. For this interpretation, the impact of stratification is one of demographic and potentially service differences, which certainly merits further research with a larger cohort.

Although this study did not show strong associations justifying changes in clinical practice, it does provide a platform for further research to explore the use of different rurality scores on cancer progression in some situations in future. Many of the differences observed in the literature that have been noted in urban and rural populations have tended to come about due to demographic and socioeconomic characteristics of the groups rather than physical remoteness and immediate access to healthcare facilities (Obertova et al., 2012) Researchers need to carefully select definitions of rurality, including other factors which affect access to diagnostic 
Diversity of Research in Health Journal / Revue de la Diversité de la Recherche en Santé

Vol 1, pp 1-16, April 2017

and treatment services, and attempt to understand the effects that this choice may or may not have on their outcome measures.

\section{References}

Alam, N., You, H., Banks, C., Baker, D., \& Bishop, J. (2009). Prostate Cancer in New South Wales. Sydney: Cancer Institute NSW.

Baade, P. D., Youlden, D. R., Coory, M. D., Gardiner, R. A., \& Chambers, S. K. (2011). Urbanrural differences in prostate cancer outcomes in Australia: what has changed. Medical Journal of Australia, 194(6), 293-296.

Boorjian, S. A., Tollefson, M. K., Rangel, L., Bergstralh, E., \& Karnes, R. J. (2012). Clinicopathological predictors of systemic progression and prostate cancer mortality in patients with a positive surgical margin at radical prostatectomy. Prostate Cancer and Prostatic Diseases, 15(1), 56-62.

Boorjian, S. A., Tollefson, M. K., Thompson, R. H., Rangel, L. J., Bergstralh, E. J., \& Karnes, R. J. (2012). Natural history of biochemical recurrence after radical prostatectomy with adjuvant radiation therapy. The Journal of Urology, 188(5), 1761-1766.

Bruce, D., Halseth, G., Giesbrecht, K., \& Yen, J. (2004). Economic Development Framework of Small Communities in Canada. Canada Mortgage and Housing Corporation. Retrieved from

http://www.unbc.ca/sites/default/files/assets/community_development_institute/research/ ecdevfw/phase_1_append_1.pdf.

Buhmeida, A., Pyrhönen, S., Laato, M., \& Collan, Y. (2006). Prognostic factors in prostate cancer. Diagnostic pathology, 1(1), 1.

Canadian Cancer Society's Advisory Committee on Cancer Statistics [CCS]. (2015). Canadian Cancer Stastics 2013: Special Topic Predictions of the future burden of cancer in Canada. Retrieved from https://www.cancer.ca/ /media/cancer.ca/CW/cancer information/cancer 101/Canadian cancer statistics/Canadian-Cancer-Statistics-2015EN.pdf

Canadian Cancer Society's Advisory Committee on Cancer Statistics [CCS]. (2016). Canadian Cancer Statistics. Retrieved from http://www.cancer.ca/ /media/cancer.ca/CW/cancer information/cancer 101/Canadian cancer statistics/Canadian-Cancer-Statistics-2016EN.pdf?la=en

Cancer Care Ontario [CCO]. (2012). SEER * Stat - OCRIS. Release 12. Retrieved from https://www.cancercare.on.ca/cancerfacts.

Carozzi, F., Lombardi, F., Zendron, P., Confortini, M., Sani, C., Bisanzi, S., . . . Ciatto, S. (2003). Association of human papillomavirus with prostate cancer: analysis of a consecutive series of prostate biopsies. The International Journal of Biological Markers, 19(4), 257-261.

Coory, M. D., \& Baade, P. D. (2005). Urban-rural differences in prostate cancer mortality, radical prostatectomy and prostate-specific antigen testing in Australia. Medical Journal of Australia, 182(3), 112-115.

Couper, I. (2003). Rural hospital focus: defining rural. Rural Remote Health, 3(2), 205.

Davidsson, S., Mölling, P., Rider, J. R., Unemo, M., Karlsson, M. G., Carlsson, J., . . A Andrén, O. (2016). Frequency and typing of Propionibacterium acnes in prostate tissue obtained from men with and without prostate cancer. Infectious Agents and Cancer, 11(1), 1. 
Diversity of Research in Health Journal / Revue de la Diversité de la Recherche en Santé Vol 1, pp 1-16, April 2017

Desmeules, M., Pong, R. W., Lagacé, C., Heng, D., Manuel, D., Pitblado, R., . . . Koren, I. (2006). How Healthy are Rural Canadians? An Assessment of Their Health Status and Health Determinants. Canadian Institute for Health Information [CIHI]. Retrieved from https://secure.cihi.ca/free_products/rural_canadians_2006_report_e.pdf.

du Plessis, V., Beshiri, R., Bollman, R. D., \& Clemenson, H. (2001). Definitions of Rural. Rural and Small Town Canada Analysis Bulletin. Retrieved from http://www.communityaccounts.ca/communityaccounts/ca_google_maps/PDF_Links/Sta ts_Canada_Definition_of_Rural_2006.pdf.

du Plessis, V., Beshiri, R., Bollman, R. D., \& Clemenson, H. (2002). Agriculture and Rural Working Paper Series Working Paper No. 61: Definitions of "Rural”. Statistics Canada, Agriculture Division. Retrieved from http://www.statcan.gc.ca/pub/21-601m/2002061/4224867-eng.pdf.

Ferris-i-Tortajada, J., Garcia-i-Castell, J., Berbel-Tornero, O., \& Ortega-Garcia, J. (2011). Constitutional risk factors in prostate cancer. Actas Urológicas Españolas (English Edition), 35(5), 282-288.

Furuya, Y., Akimoto, S., Akakura, K., \& Ito, H. (1998). Smoking and obesity in relation to the etiology and disease progression of prostate cancer in Japan. International Journal of Urology, 5(2), 134-137.

Hart, L. G., Larson, E. H., \& Lishner, D. M. (2005). Rural definitions for health policy and research. American Journal of Public Health, 95(7), 1149-1155.

Health Force Ontario [HFO]. (2015, 2015). Rural Physician Eligibility Requirements. Retrieved from

http://www.healthforceontario.ca/en/Home/Physicians/Training_\%7C_Practising_in_Ont ario/Locum/Rural_Family_Medicine_Locum_Program/Rural_Physicians/Eligibility.

Jemal, A., Ward, E., Wu, X., Martin, H. J., McLaughlin, C. C., \& Thun, M. J. (2005).

Geographic patterns of prostate cancer mortality and variations in access to medical care in the United States. Cancer Epidemiology Biomarkers \& Prevention, 14(3), 590-595.

Klein, E. A., \& Silverman, R. (2008). Inflammation, infection, and prostate cancer. Current Opinion in Urology, 18(3), 315-319.

Kralj, B. (2009). Measuring Rurality-RIO 2008_BASIC: Methodology and Results. Toronto, ON: Ontario Medical Association Economics Department.

Leung, J., McKenzie, S., Martin, J., \& McLaughlin, D. (2014). Effect of rurality on screening for breast cancer: a systematic review and meta-analysis comparing mammography. Rural and Remote Health, 14, 2730.2731-2730.2713.

Lightfoot, N. (2008, 2008). [R. Bissett Verbal Conversation].

Lightfoot, N. (2009, 2009). [R. Pitblado Verbal Communication].

Lightfoot, N., Conlon, M., Kreiger, N., Sass-Kortsak, A., Purdham, J., \& Darlington, G. (2004). Medical history, sexual, and maturational factors and prostate cancer risk. Annals of Epidemiology, 14(9), 655-662.

Mahoney, M. C., Labrie, D. S., Nasca, P. C., Wolfgang, P. E., \& Burnett, W. S. (1990). Population density and cancer mortality differentials in New York State, 1978-1982. International Journal of Epidemiology, 19(3), 483-490.

Mallah, K. N., DiBlasio, C. J., Rhee, A. C., Scardino, P. T., \& Kattan, M. W. (2005). Body mass index is weakly associated with, and not a helpful predictor of, disease progression in men with clinically localized prostate carcinoma treated with radical prostatectomy. Cancer, 103(10), 2030-2034. 
Diversity of Research in Health Journal / Revue de la Diversité de la Recherche en Santé

Vol 1, pp 1-16, April 2017

McLafferty, S., \& Wang, F. (2009). Rural reversal? Cancer, 115(12), 2755-2764.

Medicode (Firm). (1996). ICD-9-CM: International Classification of Diseases, 9th Revision, clinical modification. Salt Lake City, Utah: Medicode.

Monroe, A. C., Ricketts, T. C., \& Savitz, L. A. (1992). Cancer in rural versus urban populations: a review. The Journal of Rural Health, 8(3), 212-220.

National Cancer Institute [NCI]. (2013). Surveillance Epidemiology and End Results. SEER Stat Fact Sheets: $2012 . \quad$ Prostate Retrieved from http://seer.cancer.gov/statfacts/html/prost.html

Obertova, Z., Brown, C., Holmes, M., \& Lawrenson, R. (2012). Prostate cancer incidence and mortality in rural men-a systematic review of the literature. Rural Remote Health, 12(2), 2039.

Pampalon, R., Martinez, J., \& Hamel, D. (2006). Does living in rural areas make a difference for health in Quebec? Health \& Place, 12(4), 421-435.

Pantarotto, J., Malone, S., Dahrouge, S., Gallant, V., \& Eapen, L. (2007). Smoking is associated with worse outcomes in patients with prostate cancer treated by radical radiotherapy. $B J U$ International, 99(3), 564-569.

Ploussard, G., Epstein, J. I., Montironi, R., Carroll, P. R., Wirth, M., Grimm, M.-O., . . . Erbersdobler, A. (2011). The contemporary concept of significant versus insignificant prostate cancer. European Urology, 60(2), 291-303.

Pong, R. W., DesMeules, M., \& Lagacé, C. (2009). Rural-urban disparities in health: how does Canada fare and how does Canada compare with Australia? Australian Journal of Rural Health, 17(1), 58-64.

Rhee, H., Vela, I., \& Chung, E. (2016). Metabolic Syndrome and Prostate Cancer: a Review of Complex Interplay Amongst Various Endocrine Factors in the Pathophysiology and Progression of Prostate Cancer. Hormones and Cancer, 7(2), 75-83. doi:10.1007/s12672015-0238-X

Roach, M., Weinberg, V., Nash, M., Sandler, H., McLaughlin, P., \& Kattan, M. (2006). Defining high risk prostate cancer with risk groups and nomograms: implications for designing clinical trials. The Journal of Urology, 176(6), S16-S20.

Shugarman, L. R., Sorbero, M. E., Tian, H., Jain, A. K., \& Ashwood, J. S. (2008). An exploration of urban and rural differences in lung cancer survival among Medicare beneficiaries. American Journal of Public Health, 98(7), 1280-1287.

Singh, G. K., Williams, S. D., Siahpush, M., \& Mulhollen, A. (2012). Socioeconomic, ruralurban, and racial inequalities in US cancer mortality: Part I-All cancers and lung cancer and Part II-Colorectal, prostate, breast, and cervical cancers. Journal of Cancer Epidemiology, 2011.

StataCorp. (2015). Stata Statistical Sofware: Release 14. College Station, TX: StataCorp LP.

Statistics Canada. (2012). Postal code conversion file (PCCF), reference guide: May 2011 postal codes. (Catalogue No. 92-153-G no 02.). Ottawa, ON: Minister of Industry

Sutcliffe, S., Nevin, R. L., Pakpahan, R., Elliott, D. J., Langston, M. E., De Marzo, A. M., . . . Sokoll, L. J. (2016). Infectious mononucleosis, other infections and prostate-specific antigen concentration as a marker of prostate involvement during infection. International Journal of Cancer.

Thames, H., Kuban, D., Levy, L., Horwitz, E. M., Kupelian, P., Martinez, A., . . Shipley, W. (2003). Comparison of alternative biochemical failure definitions based on clinical outcome in 4839 prostate cancer patients treated by external beam radiotherapy between 
Diversity of Research in Health Journal / Revue de la Diversité de la Recherche en Santé

Vol 1, pp 1-16, April 2017

1986 and 1995. International Journal of Radiation Oncology* Biology* Physics, 57(4), 929-943.

Tolonen, T. T., Kujala, P. M., Tammela, T. L., Tuominen, V. J., Isola, J. J., \& Visakorpi, T. (2011). Overall and worst gleason scores are equally good predictors of prostate cancer progression. BMC Urology, 11(1), 1.

United States Department of Agriculture Economic Research Service [USDA]. (2014). Ruralurban continuum codes. Retrieved from http://www.ers.usda.gov/data-products/ruralurban-continuum-codes.aspx - .UgL1_awS9sM.

Venkitaraman, R., Norman, A., Woode-Amissah, R., Fisher, C., Dearnaley, D., Horwich, A., . . . Parker, C. (2007). Predictors of histological disease progression in untreated, localized prostate cancer. The Journal of Urology, 178(3), 833-837.

Zu, K., \& Giovannucci, E. (2009). Smoking and aggressive prostate cancer: a review of the epidemiologic evidence. Cancer Causes \& Control, 20(10), 1799-1810. 